

\section{NOTICE}

The submitted manuscript has been offered by an employee of the Alliance for Sustainable Energy, LLC (ASE), a contractor of the US Government under Contract No. DE-AC36-08-GO28308. Accordingly, the US Government and ASE retain a nonexclusive royalty-free license to publish or reproduce the published form of this contribution, or allow others to do so, for US Government purposes.

This report was prepared as an account of work sponsored by an agency of the United States government. Neither the United States government nor any agency thereof, nor any of their employees, makes any warranty, express or implied, or assumes any legal liability or responsibility for the accuracy, completeness, or usefulness of any information, apparatus, product, or process disclosed, or represents that its use would not infringe privately owned rights. Reference herein to any specific commercial product, process, or service by trade name, trademark, manufacturer, or otherwise does not necessarily constitute or imply its endorsement, recommendation, or favoring by the United States government or any agency thereof. The views and opinions of authors expressed herein do not necessarily state or reflect those of the United States government or any agency thereof.

Available electronically at http://www.osti.gov/bridge

Available for a processing fee to U.S. Department of Energy and its contractors, in paper, from:

U.S. Department of Energy

Office of Scientific and Technical Information

P.O. Box 62

Oak Ridge, TN 37831-0062

phone: 865.576.8401

fax: 865.576 .5728

email: mailto:reports@adonis.osti.gov

Available for sale to the public, in paper, from:

U.S. Department of Commerce

National Technical Information Service

5285 Port Royal Road

Springfield, VA 22161

phone: 800.553.6847

fax: 703.605.6900

email: orders@ntis.fedworld.gov

online ordering: http://www.ntis.gov/ordering.htm 


\title{
Verification of BModes: Rotary Beam and Tower Modal Analysis Code
}

\author{
Gunjit Bir \\ National Renewable Energy Laboratory, Golden, Colorado
}

\begin{abstract}
This paper describes verification of BModes, a finite-element code developed to provide coupled modes for the blades and tower of a wind turbine. The blades, which may be rotating or nonrotating, and the towers, whether onshore or offshore, are modeled using specialized 15-dof beam finite elements. Both blade and tower models allow a tip attachment, which is assumed to be rigid body with six moments of inertia, and a mass centroid that may be offset from the blade or tower axis. Examples of tip attachments are aerodynamic brakes for blades and nacelle-rotor subassembly for towers. BModes modeling allows for tower supports including tension wires, floating platforms, and monopiles on elastic foundations. Coupled modes (implying coupling of flap, lag, axial, and torsional motions) are required for modeling major flexible components in a modal-based, aeroelastic code such as FAST ${ }^{1}$. These are also required for validation of turbine models using experimental data, modal-based fatigue analysis, controls design, and understanding aeroelastic-stability behavior of turbines. Verification studies began with uniform tower models, with and without tip inertia, and progressed to realistic towers. For the floating turbine, we accounted for the effects of hydrodynamic inertia, hydrostatic restoring, and mooring lines stiffness. For the monopole-supported tower, we accounted for distributed hydrodynamic mass on the submerged part of the tower and for distributed foundation stiffness. Finally, we verified a model of a blade carrying tip mass and rotating at different speeds (verifications of other blade models, rotating or non-rotating, have been reported in another paper ${ }^{2}$ ). Verifications were performed by comparing BModes-generated modes with analytical results, if available, or with MSC.ADAMS ${ }^{\circledR}$ results. All results in general show excellent agreement.
\end{abstract}

\section{Introduction}

BModes is a finite-element code developed for high-fidelity modal analysis of a wind turbine's blade or tower, whether offshore or onshore. Both the blade, rotating or non-rotating, and the tower may have an arbitrary distribution of structural properties. Both blade and tower models allow a tip attachment, which is assumed to be rigid body with six moments of inertia, and a mass centroid that may be offset from the blade or tower axis. Examples of tip attachments are aerodynamic brakes for blades and nacelle-rotor subassemblies for towers. In addition, the blade may have a precone and an arbitrary pitch-control setting. For the tower, BModes allows five configurations: a land-based tower, an offshore monopile-supported tower, an offshore floatingbarge-supported tower, an offshore tension-leg-supported tower, and an offshore spar-buoysupported tower. Figure 1 shows the three floating turbine configurations. Optionally, the landbased tower may have tension support wires.

The modes of a blade or a tower are generally coupled, which implies the presence of flexural, axial, and torsional motions in a natural mode of vibration. For the blade, flexural motion means 
flap and lag bending, whereas for the tower it means fore-aft and side-to-side bending. Coupled modes are crucial to several applications:

- modeling of major flexible components for modal-based aeroelastic codes

- dynamic characterization

- validation of turbine models using experimental data

- modal-based fatigue analysis

- in-depth interpretation of turbine aeroelastic stability.

The cause of coupling can be geometric, dynamic, or material anisotropy. ${ }^{3}$ Obtaining rotatingblade coupled modes involves solving a complex boundary-value problem, and only a few codes rigorously handle this. BModes handles it accurately because it uses a finite-element approach in conjunction with analytical linearization and a unique finite-element assembly that properly captures Coriolis and centrifugal effects. The finite-element method (FEM) is based on a 15-dof element with three internal and two boundary nodes. A salient feature of BModes is its potential to handle a complex range of boundary conditions.

The structural properties along the blade length are specified in terms of the flap bending, lag bending, torsion, axial stiffness, mass, section moments of inertia, and chordwise offsets of section shear center, tension center, and center-of-mass. These properties may be obtained from experimental tests, the blade manufacturer, or a properties-extractor code, such as $\mathrm{VABS}^{4}$, PreComp ${ }^{5}$ or BPE. ${ }^{6}$ Currently, BModes allows only metallic or isotropic composite blades. With the aforementioned inputs, the code uses the FEM followed by an eigenanalysis to compute mode shapes and frequencies.

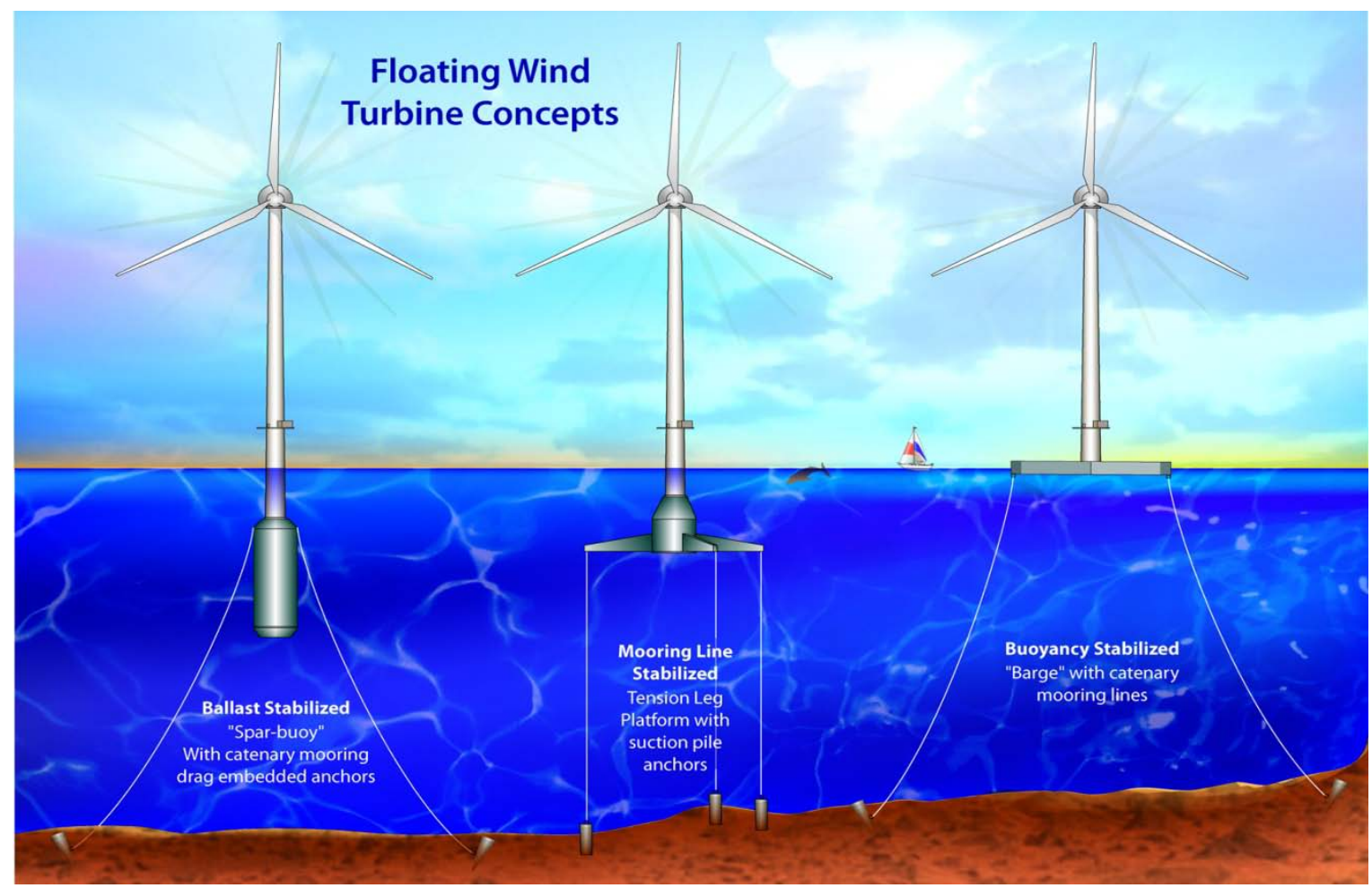

Figure 1: Floating turbine concepts 
Since its initial release, BModes ${ }^{3}$ has undergone several upgrades specifically related to offshore modeling. Examples of the upgrades include:

- extension of the FEM model to include distributed hydrodynamic added mass and elastic foundation stiffness

- inclusion of floating-platform and monopile-support DOF

- inclusion of gravity effects.

In addition, a rigid-body finite element was introduced to model floating platforms subject to added hydrodynamic inertia, hydrostatic stiffness (buoyancy matrix), and mooring-line stiffness. The influence of gravity on the modes of an offshore turbine can be significant.

This paper verifies BModes modal analysis capability for towers and blades with tip inertias (verification of other blade models has been covered in another paper). Section II provides a brief description of BModes and its modeling and analysis approach. Section III presents verification of its tower modal analysis capability. We compare results from BModes with those from MSC.ADAMS ${ }^{\circledR}$. Section IV presents verification results for a spinning blade carrying a tip mass. The paper concludes with a summary of the results and an outline of future plans.

\section{A Brief Description of BModes}

BModes computes coupled modes for blades and towers using a finite-element approach. Both the blade and the tower are modeled as Euler-Bernoulli beams, which can have an arbitrary distribution of geometry and structural properties along their length. The properties are specified in terms of stiffness (flexural, torsional, and axial), section mass, section moments of inertia, and chordwise offsets of section shear center, tension center, and center-of-mass variation along the blade. The stiffness properties are defined with respect to principal axes centered at the shear center. The inertia properties are defined with respect to the principal inertia axes centered at the mass centroid. The orientation of each set of principal axes and the built-in blade twist may also vary along the blade. Rotary inertia and certain nonlinear stiffness effects are accounted for in the code. Currently, the code allows only metallic or isotropic composite blades. Both the blade and the tower may have end attachments. An end attachment is modeled as a rigid body with mass, six moments of inertia, and a mass centroid that may be offset from the blade or tower axis.

As mentioned earlier, BModes has recently been upgraded to handle offshore turbines. The tower may be supported on a sea-floating platform or on a monopile embedded in the seabed. The floating platform may be subjected to hydrodynamic-added mass, hydrostatic restoring, and mooring line stiffness. The added mass and stiffness are generally distinct from physical inertias and springs and are expressed as 6X6 matrices associated with the six DOF (three translational and three rotational). For a monopile support, the soil effect is modeled as a distributed stiffness along the soil-buried part of the tower. Also, hydrodynamic-added mass may be specified along the submerged part of the tower, i.e., the part of the tower between the mean sea level (MSL) and the mudline.

Accurately obtaining rotating-blade or tower coupled modes is a challenging boundary-value problem, and only a few codes handle it rigorously. BModes modeling is high fidelity, using a finite-element approach in conjunction with analytical linearization and a special finite-element assembly that accurately captures Coriolis and centrifugal effects. Its finite-element approach, 
built on $\mathrm{UMARC}^{7}$, uses a 15- DOF element with three internal and two boundary nodes. The 15 DOFs comprise 3 DOFs for torsion deflection and 4 DOFs each for axial, flap, and lag deflections (Figure 2). In the figure, $u, v, w$, and $\phi$ represent the axial, tower fore-aft, tower sideside, and twist DOF, respectively.

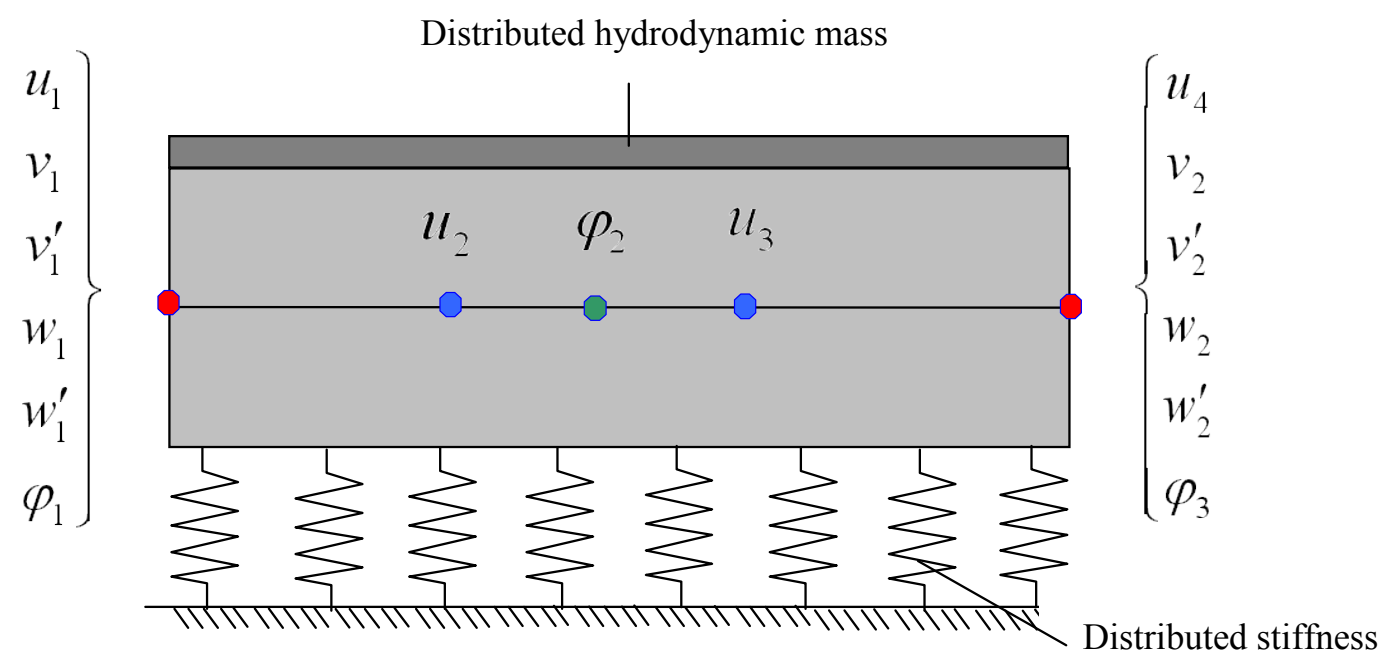

Figure 2. The 15-DOF finite element

The new finite element accounts for distributed stiffness and added mass, which may arise for platform- and monopile-supported towers. The distributed hydrodynamic added mass is effective only in the lateral directions $(v, w)$ and not in the torsional and axial directions. The distributed stiffness, like the distributed added mass, may vary along the element length and it also may be different in the two lateral directions (normal to the element axis). The blade tip inertia, the tower head (nacelle-rotor subsystem) and the tower base attachment (e.g., floating barge) are modeled using rigid-body elements.

A full discussion of the BModes theory basis is outside the scope of this paper. However, Figure 3 outlines the technical approach. First, we idealize the blade or the tower as an Euler-Bernoulli beam that undergoes bending, elastic twist, and axial deflections. Next, we formulate energy expressions and use Hamilton's principle to derive coupled integro-partial differential equations (PDEs) governing the dynamics of the elastic beam attached to rigid end inertias. 


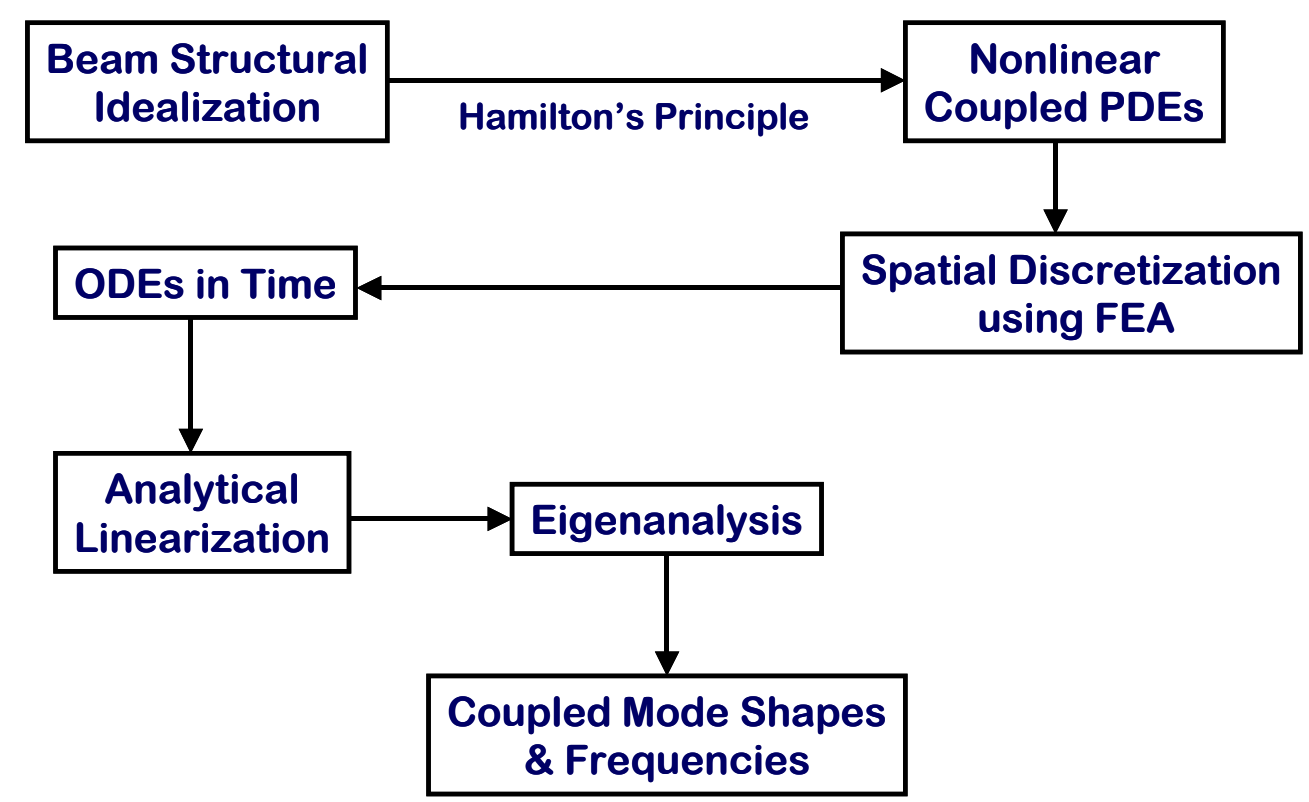

Figure 3. Technical approach: computation of tower coupled modes

These PDEs are nonlinear and include spatial integral terms, which represent Coriolis and centrifugal effects. We use finite element analysis (FEA) to discretize the spatial variables in the PDEs. This FEA is compatible with Hamilton's principle. The beam is divided into 15-DOF elements. Continuity of displacement and slope for bending deflections and continuity of displacement for elastic twist and axial deflections are maintained between elements. The elastic twist is represented by a quasi-coordinate (non-Euler); this eliminates axial integral terms that otherwise would appear in orientation matrices for an elastic beam. Finite elements assembly, specialized for integro-partial differential equations, followed by application of appropriate boundary conditions, yields nonlinear ordinary differential equations (ODEs) in nodal coordinates. Analytical linearization (distinct from finite-differencing) yields inertia and stiffness matrices. Finally, we perform an eigenanalysis to obtain coupled modes and frequencies.

\section{Verification of Tower Modal Analysis Capability}

Because accurate modes play a crucial role in several applications, we performed extensive verification studies on BModes - those related to blades have already been reported ${ }^{2}$, though in part only. This paper presents the remaining result for the blades. We also present verification results for the tower, which is the focus of this section. As mentioned in the previous section, tower modal analysis capability necessitated several extensions to BModes. The geometric and structural properties of the tower configurations used in the verification studies are available in Ref. 11. The tower head (rotor-nacelle subsystem) is the same for all configurations and its properties are also listed in the same reference.

We first used BModes to build simple tower models (e.g. uniform and tapered beams with end masses) and compared the modal results with those from analytical models. Excellent agreement was obtained for all models (results are not shown here to keep the paper length short, but will be 
included later in a publically available report). For a more realistic verification, we built several tower models using BModes and MSC.ADAMS ${ }^{\circledR}$. Sample verification results are presented below.

\subsection{Land-Based Tower (with and without rotor-nacelle head mass)}

We modeled the land-based tower as a beam cantilevered to the ground and computed its natural frequencies and mode shapes. Table 1 lists the modal frequencies of the tower (with and without the rotor-nacelle head mass) and also compares these with frequencies obtained from the ADAMS models. We used 50 finite elements in BModes and 99 tower parts in ADAMS. The head mass was idealized as a rigid body in both BModes and ADAMS.

The modal frequencies are shown to four decimal points to aid verification. All frequencies, except very high ones, show good agreement. Also, for the tower with no head mass, note that BModes predicts $i^{\text {th }} \mathrm{F}$-A and $i^{\text {th }} \mathrm{S}$-A modal frequencies to be identical, as should be the case. Similar results from ADAMS differ, though by a very small margin. We believe BModescomputed results, particularly for higher modes, are more accurate because it uses a consistentmass approach, whereas ADAMS effectively uses a lumped mass approach. Note that the head mass substantially lowers all the modal frequencies. As mentioned earlier, the head mass (rotornacelle subsystem) is considered rigid. Flexibility of the rotor would alter the system frequencies and the mode shapes somewhat; the torsion frequencies, in particular, would be higher.

Figures 4 and 5 show the BModes-computed mode shapes for the land-based tower without and with the head mass (such modes are quantitatively difficult to extract from ADAMS). All mode shapes presented in this paper are mass-normalized. We do not normalize modes for unity tip deflection, as is typically done. This will be explained later. Also, the tower section height has been normalized with respect to $H$, the height of the flexible tower, which is $87.6 \mathrm{~m}$. Thus, zero represents the flexible tower base and one represents the tower top. Without the head mass (Figure 4), the tower fore-aft (F-A) and side-to-side (S-S) modes are identical as expected of an axi-symmetric tower. The presence of the tower head mass introduces coupling between the sideto-side and torsion motions (Figure 5b). The fore-aft modes, however, remain uncoupled (Figure 5a). Also note that the head mass substantially alters the mode shapes. The rotary inertia of the head mass results in $2^{\text {nd }}$ fore-aft and $2^{\text {nd }}$ side-to-side mode shapes with near-zero deflections at the tower tip. An attempt to normalize such modes for unit tip deflections may lead to errorprone mode shapes. In fact, if the tip deflection were exactly zero (possible in reality), it would be impossible to normalize modes for unity deflections. That is why BModes uses massnormalization.

Table 1. Modal Frequencies of Land-Based Tower with and without Head Mass.

\begin{tabular}{|c|c|c|c|c|c|c|c||}
\hline \multirow{3}{*}{$\begin{array}{c}\text { Mode } \\
\text { Number }\end{array}$} & \multirow{2}{*}{$\begin{array}{c}\text { Mode } \\
\text { Type }\end{array}$} & \multicolumn{3}{|c|}{ Without Head Mass } & \multicolumn{3}{c||}{ With Head Mass } \\
\cline { 3 - 8 } & & \multicolumn{2}{|c|}{ Frequency (Hz) } & \multicolumn{3}{|c|}{ Frequency(Hz) } \\
\cline { 3 - 8 } & & BModes & ADAMS & Diff & BModes & ADAMS & Diff \\
\hline \hline 1 & 1st SS & 0.8913 & 0.8904 & 0.001 & 0.3291 & 0.3188 & 0.010 \\
\hline 2 & 1st FA & 0.8913 & 0.8904 & 0.001 & 0.3324 & 0.3218 & 0.011 \\
\hline 3 & 2ndSS & 4.3743 & 4.3437 & 0.031 & 1.8805 & 1.8820 & 0.002 \\
\hline 4 & 2nd FA & 4.3743 & 4.3435 & 0.031 & 2.2432 & 2.2391 & 0.004 \\
\hline 5 & 3rd SS & 11.3911 & 11.1856 & 0.205 & 4.6526 & 4.7244 & 0.072 \\
\hline 6 & 3rd FA & 11.3911 & 11.1843 & 0.207 & 4.9865 & 5.1833 & 0.197 \\
\hline 7 & 1st Torsion & 11.9656 & 11.4448 & 0.521 & 1.4703 & 1.4763 & 0.006 \\
\hline 8 & 1st Axial & 16.5217 & 16.5222 & 0.001 & 8.1311 & 7.9375 & 0.194 \\
\hline
\end{tabular}




\begin{tabular}{||c|c|c|c|c|c|c|c||}
\hline 9 & 4th SS & 21.8655 & 21.1146 & 0.751 & 11.3142 & 11.2678 & 0.046 \\
\hline 10 & 4th FA & 21.8655 & 21.1093 & 0.756 & 11.4591 & 11.4719 & 0.013 \\
\hline 11 & 2nd Torsion & 27.7783 & 26.1221 & 1.656 & 17.9632 & 17.9535 & 0.010 \\
\hline 12 & 5th SS & 35.8273 & 33.8392 & 1.988 & 21.7054 & 21.3291 & 0.376 \\
\hline 13 & 5th FA & 35.8273 & 33.8236 & 2.004 & 21.7625 & 21.4419 & 0.321 \\
\hline 14 & $2^{\text {nd }}$ Axial & 43.4596 & 42.1715 & 1.288 & 30.2109 & 30.1182 & 0.093 \\
\hline 15 & $3^{\text {rd }}$ Torsion & 44.8623 & 43.4578 & 1.405 & 35.3975 & 34.5078 & 0.890 \\
\hline 16 & 6th SS & 53.2770 & 48.9445 & 4.332 & 35.6336 & 34.5830 & 1.051 \\
\hline 17 & 6th FA & 53.2770 & 48.9071 & 4.370 & 35.6636 & 35.3740 & 0.290 \\
\hline 18 & $4^{\text {th }}$ Torsion & 62.2312 & 58.6564 & 3.575 & 52.9449 & 50.5171 & 2.428 \\
\hline 19 & $3^{\text {rd }}$ Axial & 71.4741 & 65.8776 & 5.596 & 53.0811 & 52.8981 & 0.183 \\
\hline 20 & $7^{\text {th }}$ SS & 74.2155 & 65.9541 & 8.261 & 53.0673 & 50.5720 & 2.495 \\
\hline \hline
\end{tabular}

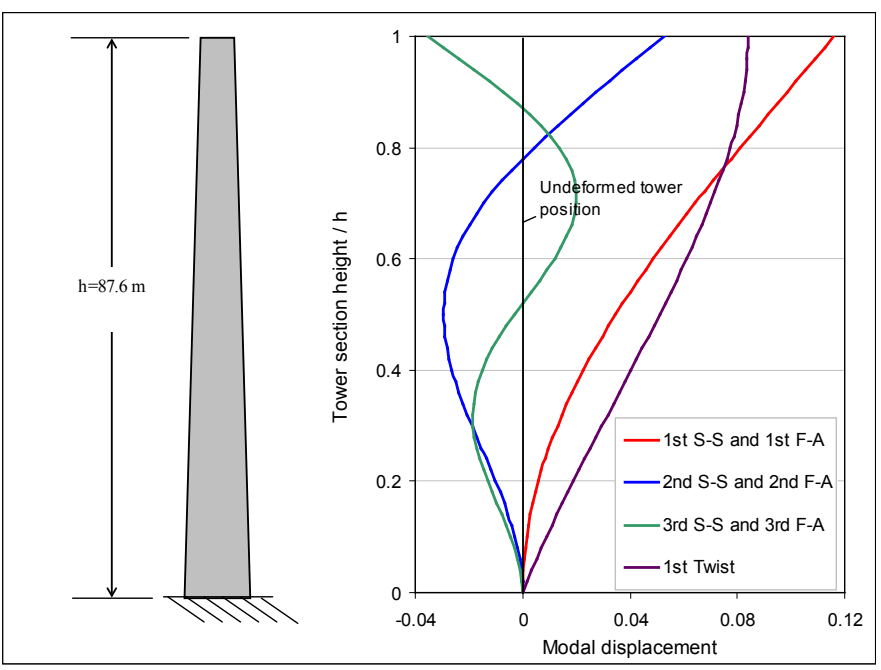

Figure 4. Modes of land-based turbine tower without head mass

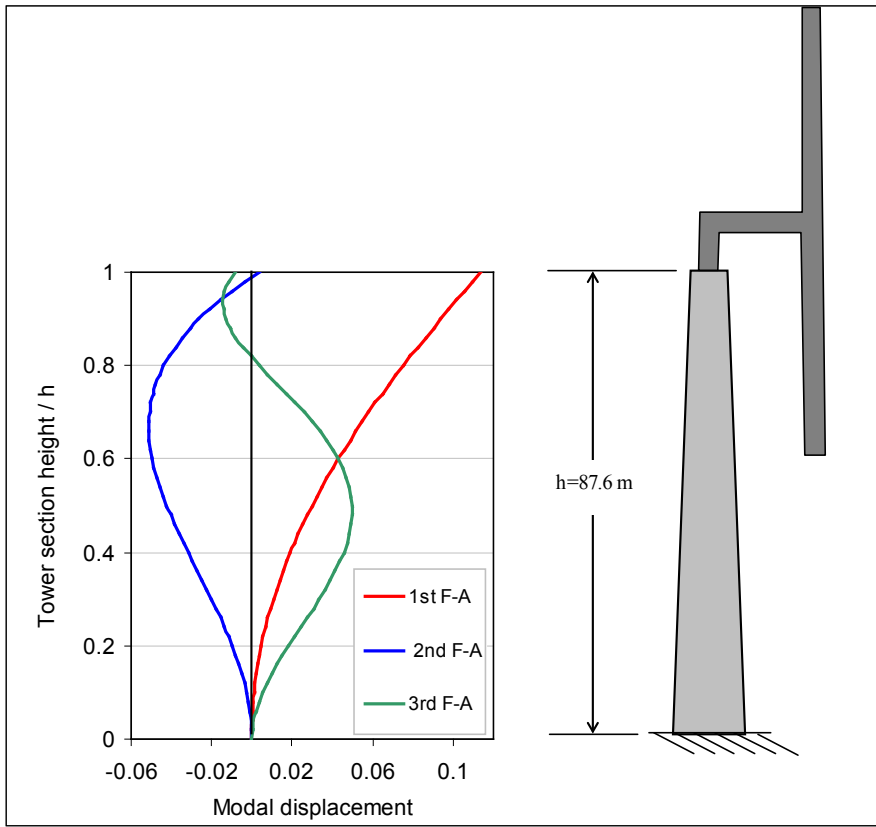

Figure 5a. Fore-aft modes of land-based tower with head mass 


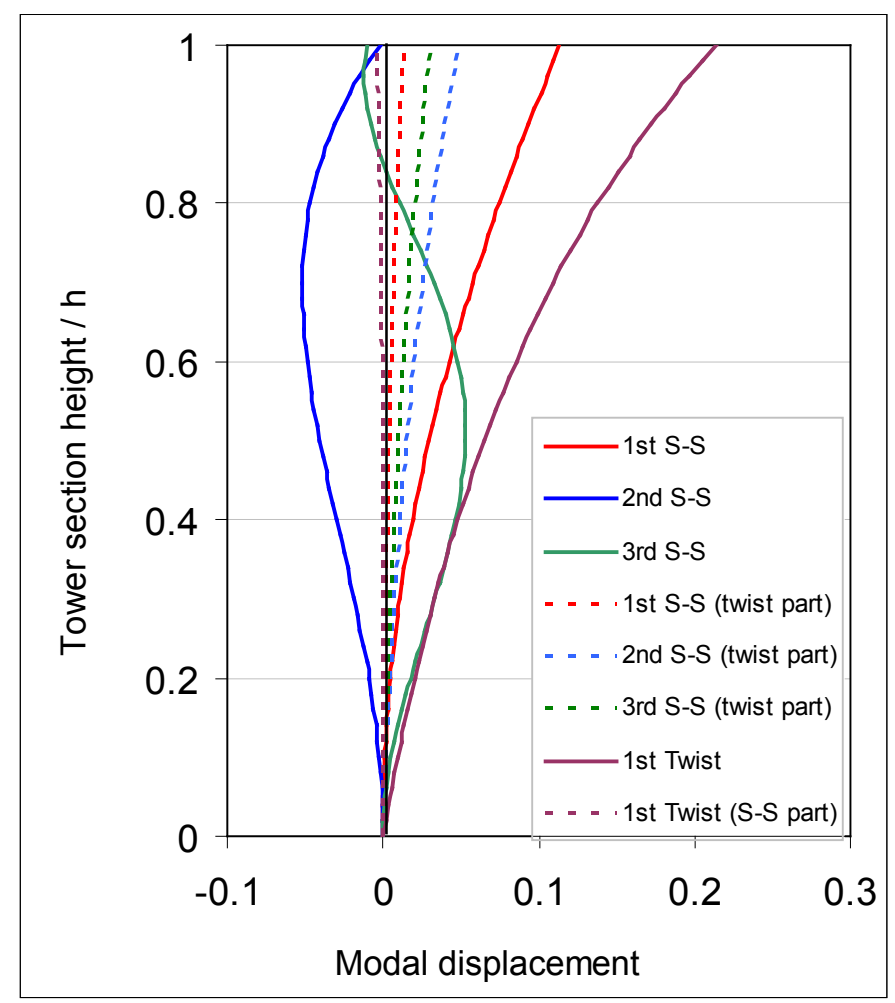

Figure 5b. Coupled side-to-side and twist modes for the land-based tower

\subsection{Floating-Barge-Supported Tower}

Using BModes, we model the floating-barge-supported turbine as a beam with all the six DOF (three translational and three rotational) unconstrained at both ends. The tower-top end of the beam carries head mass and the tower-base end carries the platform modeled as a rigid body. The barge is a rectangular box and is attached to eight mooring lines (two at each end). In the static equilibrium position, the top surface of the platform (barge) coincides with the mean sea surface. To account for the hydrodynamic and hydrostatic effects on the platform, $6 \times 6$ inertia (added mass) and 6x6 restoring (stiffness) matrices, obtained from $\mathrm{WAMIT}^{8}$, are input to BModes. The added mass values were chosen to be the values in the added mass matrix at the infinitefrequency limit of the frequency-dependent solution to the wave-radiation problem. A $6 \times 6$ matrix accounting for the mooring system stiffness is also included within BModes. This matrix was found by numerically linearizing the nonlinear mooring system module of FAST. ${ }^{1}$ Because this particular configuration has no sea-submerged tower part, no distributed added mass (hydrodynamic) effect was included. Table 2 lists modal frequencies for the three platform models: platform inertia only (platform physical inertia without hydrodynamic added mass or stiffness), platform with all effects except the added mass, and the full platform model.

In Table 2, the surge mode is the fore-aft motion of the platform, sway is the side-to-side motion, heave is the up-down motion, yaw is the rotational motion about the tower axis, roll is the rotational motion about the platform longitudinal axis, and pitch is the rotational motion about the platform lateral axis. In the absence of any added mass and spring forces on the platform (platform-inertia-only model), the turbine behaves as a free-free flexible beam with two end inertias. Consequently, six zero-frequency, rigid-body modes were observed. Note that the added 
hydrodynamic mass lowers all frequencies somewhat. The heave mode is substantially lower (from $0.2576 \mathrm{~Hz}$ to $0.1283 \mathrm{~Hz}$ ). The last column in the table lists ADAMS-computed frequencies for the full platform model. All frequencies agree well, except the heave frequency (identified in blue in the table). This result is because the ADAMS linearized model admits only a physical mass and inertia, whereas BModes permits the use of both physical and added masses. To account for the additional (hydrodynamically added) mass and inertia in the ADAMS model, we augmented the physical mass and inertia and altered the c.m. location of the barge. This could not be done perfectly because the actual hydrodynamic-added mass of the barge in heave is quite different than the added mass in surge and sway (unlike the physical mass, which is identical in all directions). Augmentation of the barge body mass properties ensured that the surge, sway, pitch, roll, and yaw elements (including off-diagonal elements) - but not the heave elementaccounted for the added mass matrix in the ADAMS model.

Table 2. Modal Frequencies of Floating-Platform-Supported Turbine

\begin{tabular}{||c|c|c|c|c|c||}
\hline \hline & & \multicolumn{4}{|c|}{ Frequency (Hz) } \\
\hline \multirow{2}{*}{$\begin{array}{c}\text { Mode } \\
\text { Number }\end{array}$} & $\begin{array}{c}\text { Mode } \\
\text { Type }\end{array}$ & $\begin{array}{c}\text { Platform } \\
\text { Inertia } \\
\text { Only }\end{array}$ & $\begin{array}{c}\text { Platform Inertia + } \\
\text { Hydrostatic \& } \\
\text { Mooring Stiffness }\end{array}$ & $\begin{array}{c}\text { Full } \\
\text { Platform } \\
\text { Model }\end{array}$ & $\begin{array}{c}\text { Full } \\
\text { Platform } \\
\text { Model }\end{array}$ \\
\hline \hline 1 & Surge & 0.0000 & 0.0081 & 0.0076 & 0.0076 \\
\hline 2 & Sway & 0.0000 & 0.0081 & 0.0076 & 0.0076 \\
\hline 3 & Yaw & 0.0000 & 0.0206 & 0.0198 & 0.0198 \\
\hline 4 & Roll & 0.0000 & 0.1106 & 0.0978 & 0.0966 \\
\hline 5 & Pitch & 0.0000 & 0.1109 & 0.0980 & 0.0968 \\
\hline 6 & Heave & 0.0000 & 0.2576 & 0.1283 & 0.2463 \\
\hline 7 & 1st SS & 0.7349 & 0.7671 & 0.5489 & 0.5374 \\
\hline 8 & 1st FA & 0.7494 & 0.7820 & 0.5556 & 0.5440 \\
\hline 9 & 1st Torsion & 1.4836 & 1.4836 & 1.4826 & 1.4890 \\
\hline 10 & 2nd SS & 1.9943 & 1.9962 & 1.9270 & 1.9327 \\
\hline 11 & 2nd FA & 2.3652 & 2.3666 & 2.2942 & 2.2950 \\
\hline 12 & 3rd SS & 4.7559 & 4.7562 & 4.7011 & 4.7742 \\
\hline 13 & 3rd FA & 5.0799 & 5.0801 & 5.0293 & 5.2260 \\
\hline 14 & 1st Axial & 8.5014 & 8.5017 & 8.2186 & 8.2759 \\
\hline 15 & 4th SS & 11.3835 & 11.3835 & 11.3542 & 11.3138 \\
\hline 16 & 4th FA & 11.5280 & 11.5280 & 11.4983 & 11.5167 \\
\hline 17 & 2nd Torsion & 17.9683 & 17.9683 & 17.9679 & 17.9639 \\
\hline 18 & 5th SS & 21.7584 & 21.7584 & 21.7406 & 21.3760 \\
\hline 19 & 5th FA & 21.8153 & 21.8153 & 21.7975 & 21.4885 \\
\hline 20 & 2nd Axial & 30.4368 & 30.4368 & 30.2625 & 30.3275 \\
\hline & & & & & \\
\hline
\end{tabular}




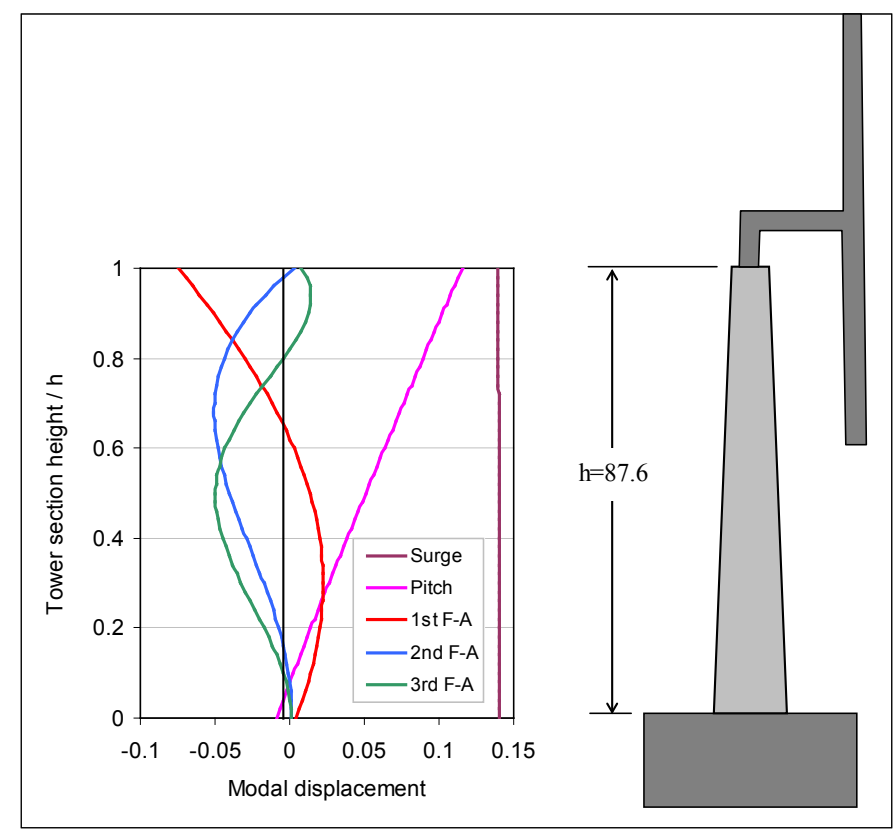

Figure 6a. Modes of platform-supported turbine

Figures 6a-6c show BModes-computed mode shapes for the full platform-supported turbine model. Note that all modes in the longitudinal plane of symmetry of the turbine are uncoupled, whereas other modes are coupled. Note also that the low-frequency platform modes (surge, etc) are close to rigid-body modes, as expected.

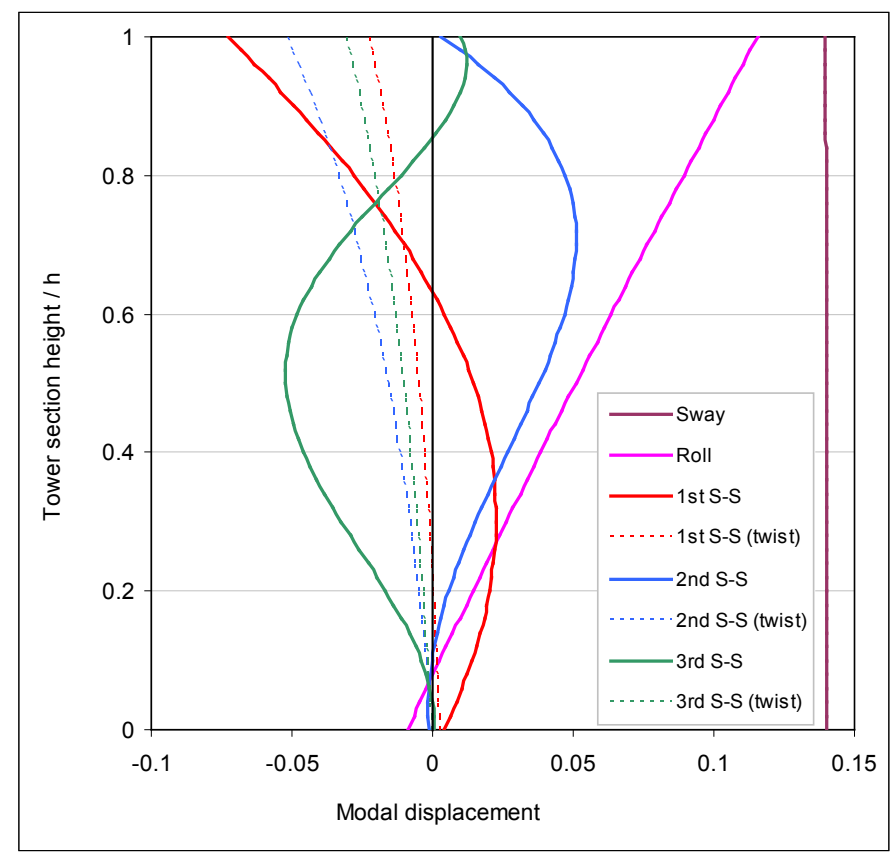

Figure 6b. Modes of platform-supported turbine 


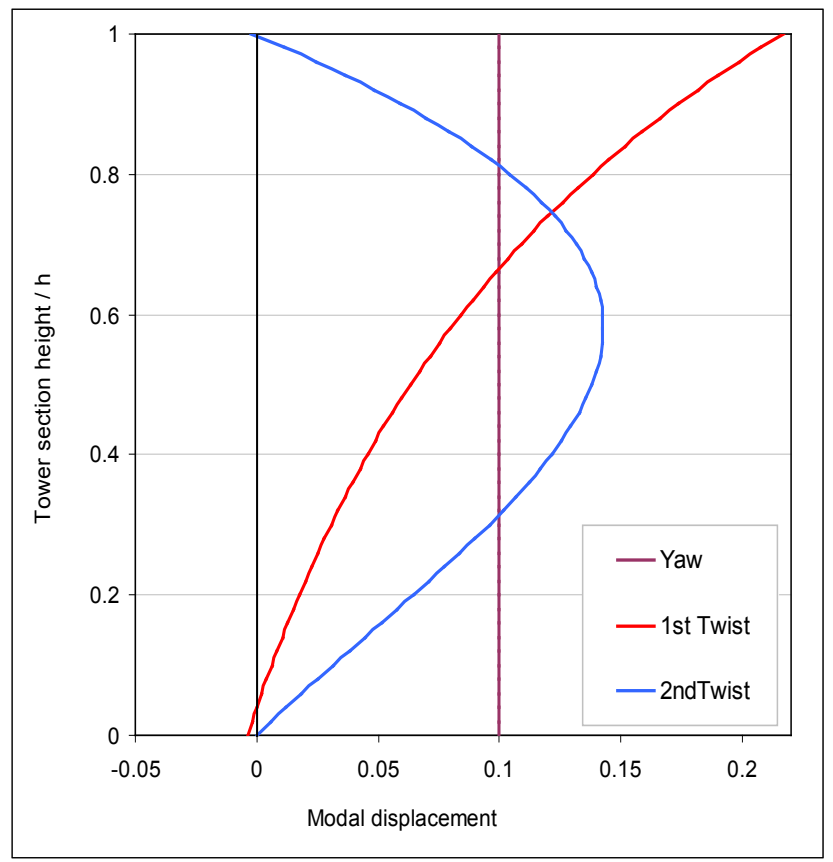

Figure 6c. Modes of platform-supported turbine

\subsection{Monopile-Supported Tower}

Figure 7 shows the monopile-supported tower and its equivalent model. The soil is modeled as a distributed spring supporting the tower base. The effect of sea water surrounding the submerged part of the tower is modeled as distributed hydrodynamic-added mass.

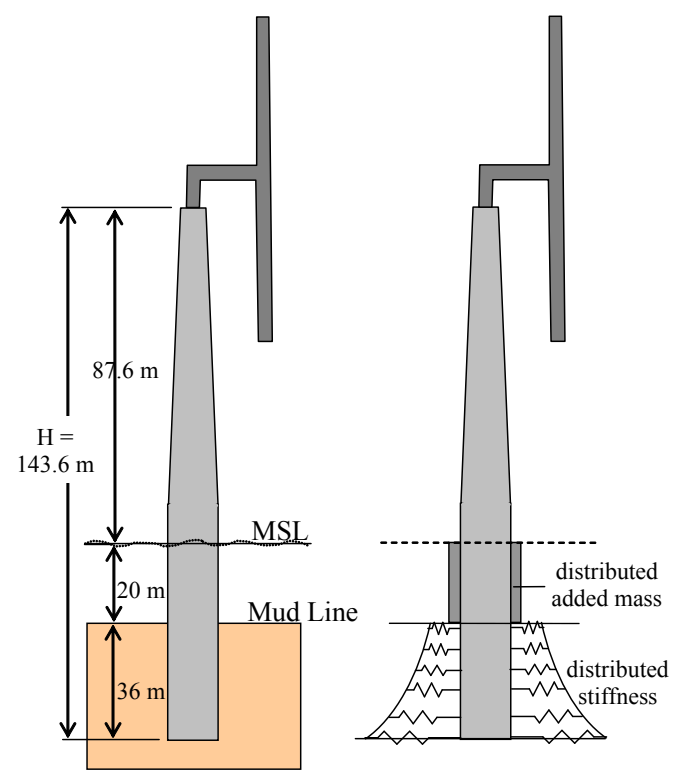

Figure 7. Monopile foundation and its equivalent model

Table 3 compares BModes- and ADAMS-computed modal frequencies. All frequencies agree well, thereby verifying BModes modeling of the elastic foundation. Figure 8 shows the first few 
modes; the tower section height has been normalized with respect to $H$, the height of the flexible tower, which is $143.6 \mathrm{~m}$.

Table 3. Comparison of BModes- and ADAMS-Predicted Frequencies for the DS Model

\begin{tabular}{||c|c|c|c|c||}
\hline \hline \multirow{2}{*}{$\begin{array}{c}\text { Mode } \\
\text { Number }\end{array}$} & \multirow{2}{*}{$\begin{array}{c}\text { Mode } \\
\text { Type }\end{array}$} & \multicolumn{2}{|c|}{ Frequency $(\mathrm{Hz})$} & Difference \\
\cline { 3 - 4 } & BModes & ADAMS & $(\mathrm{Hz})$ \\
\hline \hline 1 & 1st SS & 0.2513 & 0.2457 & 0.01 \\
\hline 2 & 1st FA & 0.2530 & 0.2472 & 0.01 \\
\hline 3 & 1 st Torsion & 1.2752 & 1.2777 & 0.00 \\
\hline 4 & 2nd SS & 1.3680 & 1.3549 & 0.01 \\
\hline 5 & 2nd FA & 1.5316 & 1.5056 & 0.03 \\
\hline 6 & 3rd SS & 2.7425 & 2.7810 & 0.04 \\
\hline 7 & 3rd FA & 3.0874 & 3.1788 & 0.09 \\
\hline 8 & 4 th SS & 5.9778 & 6.0090 & 0.03 \\
\hline 9 & 4th FA & 6.0506 & 6.2269 & 0.18 \\
\hline 10 & 1 st Axial & 6.7671 & 6.5515 & 0.22 \\
\hline 11 & 2 nd Torsion & 10.3875 & 10.3448 & 0.04 \\
\hline 12 & 5 th SS & 11.4049 & 11.2947 & 0.11 \\
\hline 13 & 5 th FA & 11.4758 & 11.4022 & 0.07 \\
\hline 14 & $6^{\text {th }}$ SS & 17.9595 & 17.6518 & 0.31 \\
\hline 15 & $6^{\text {th }}$ FA & 17.9704 & 17.7208 & 0.25 \\
\hline 16 & $2^{\text {nd }}$ Axial & 18.1887 & 18.0404 & 0.15 \\
\hline 17 & $3^{\text {rd }}$ Torsion & 21.1075 & 21.1944 & 0.09 \\
\hline 18 & $7^{\text {th }}$ SS & 26.3980 & 25.7959 & 0.60 \\
\hline 19 & $7^{\text {th }}$ FA & 26.4215 & 25.8452 & 0.58 \\
\hline 20 & $4^{\text {th }}$ Torsion & 32.9711 & 32.8559 & 0.12 \\
\hline
\end{tabular}
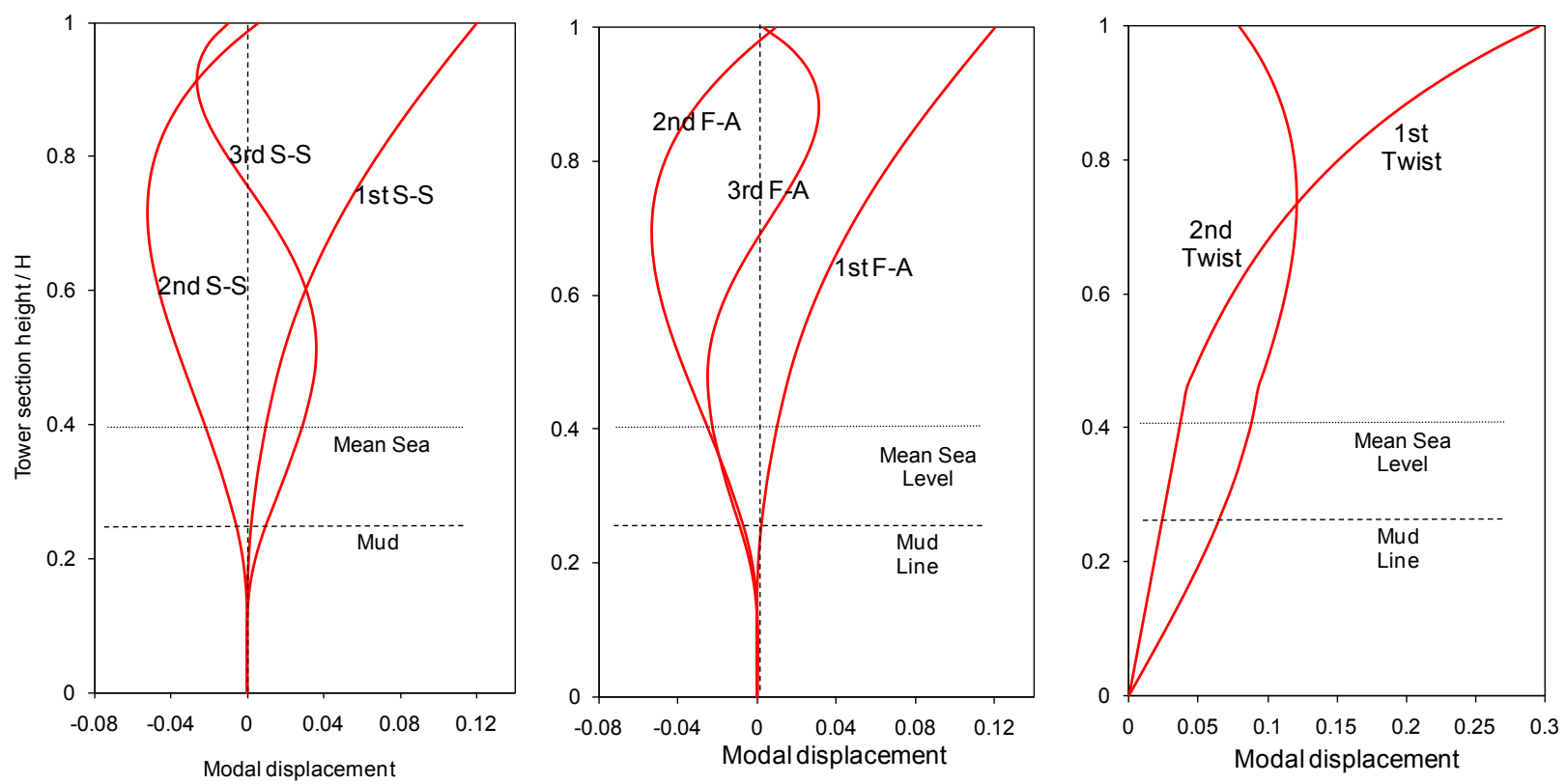

Figure 8. Mode shapes of the monopile-supported turbine 


\subsection{Spar-Buoy-Supported Tower}

Table 4 compares BModes- and ADAMS-computed modal frequencies for the spar-buoysupported turbine. The table also shows how gravity influences the modal frequencies, in particular the pitch and roll frequencies. Again, good agreement was observed between the BModes and ADAMS results except for a few modal frequencies identified in blue. As explained earlier in section III-B, this is because the ADAMS linearized model admits only a physical mass and inertia, whereas BModes permits the use of both physical and added masses. The discrepancy in the side-to-side second and third modes is perhaps due to erroneous interpretation of modes in ADAMS (investigationis underway).

Table 4. BModes- and ADAMS-Predicted Frequencies for the Spar-Buoy-Supported Tower

\begin{tabular}{||c|l|l|l|l|l||}
\hline \multirow{2}{*}{$\begin{array}{c}\text { Mode } \\
\text { Number }\end{array}$} & \multirow{2}{*}{$\begin{array}{c}\text { Mode } \\
\text { Type }\end{array}$} & $\begin{array}{c}\text { BModes } \\
\text { (no gravity) }\end{array}$ & $\begin{array}{c}\text { Bmodes } \\
\text { (with } \\
\text { gravity) }\end{array}$ & ADAMS & $\begin{array}{c}\text { Difference } \\
(\mathrm{Hz})\end{array}$ \\
\hline \hline 1 & Surge & 0.0085 & 0.0085 & 0.0084 & 0.0001 \\
\hline 2 & Sway & 0.0089 & 0.0089 & 0.0089 & 0.0000 \\
\hline 3 & Heave & 0.0324 & 0.0325 & 0.0180 & 0.0145 \\
\hline 4 & Roll & 0.0711 & 0.0376 & 0.0377 & 0.0001 \\
\hline 5 & Pitch & 0.0712 & 0.0377 & 0.0378 & 0.0001 \\
\hline 6 & Yaw & 0.1649 & 0.1649 & 0.1649 & 0.0000 \\
\hline 7 & SS-1 & 0.5000 & 0.4893 & 0.4861 & 0.0032 \\
\hline 8 & FA-1 & 0.5104 & 0.5103 & 0.5103 & 0.0000 \\
\hline 9 & Twist & 1.693 & 1.695 & 1.700 & 0.0051 \\
\hline 10 & SS-2 & 2.067 & 2.065 & 0.7647 & 1.3003 \\
\hline 11 & FA-2 & 2.569 & 2.568 & 2.562 & 0.0062 \\
\hline 12 & SS-3 & 6.029 & 6.026 & 3.720 & 2.3057 \\
\hline 13 & FA-3 & 6.360 & 6.329 & 6.326 & 0.0031 \\
\hline 14 & Axial & 8.033 & 7.678 & 7.669 & 0.0087 \\
\hline
\end{tabular}

\section{Verification of Modal Analysis of Rotating Blade with Tip Mass}

We use this model to verify that the BModes correctly captures the interaction among rotational, inertial, and elastic effects. We assume uniform structural properties along the blade with no twist and no offsets of the elastic and center-of-mass axes. The blade length, L, is $31.623 \mathrm{~m}$ and its mass $\mathrm{m}$ per unit length is $100 \mathrm{~kg} / \mathrm{m}$. Its cross-sectional flexural rigidities for flap, lag, and torsion are respectively, $10^{8} \mathrm{~N}-\mathrm{m} 2,10^{9} \mathrm{~N}-\mathrm{m} 2$, and $10^{5} \mathrm{~N}-\mathrm{m} 2$. The tip mass is $3162.3 \mathrm{~kg}$. This rather high mass is selected to allow comparison with published results. We built a BModes model for a uniform blade using 15 beam elements and computed its flap, lag, and torsion modes. Analytical results are available for the flap modes $^{9}$ of this model and we use these for comparison (see Table 5). Note that the first flap frequency variation with rotor speed, computed by BModes, shows an exact agreement with the analytical results, at least up to the significant digits shown. The higher frequencies also show excellent agreement. The largest discrepancy is about $0.02 \%$ for the second flap frequency when the blade is spinning at $12 \mathrm{rad} / \mathrm{sec}$. 
Table 5: Comparison of Flap Frequencies: Rotating Uniform Blade with Tip Mass

\begin{tabular}{|c|c|c|c|c|}
\hline \multirow{2}{*}{$\begin{array}{c}\text { Blade Spin } \\
\text { Rate, } \\
\text { प(rad/sec) }\end{array}$} & \multicolumn{2}{|c|}{$\begin{array}{c}\text { First Flap Frequency } \\
\text { (rad/sec) }\end{array}$} & \multicolumn{2}{c|}{$\begin{array}{c}\text { Second Flap Frequency } \\
\text { (rad/sec) }\end{array}$} \\
\cline { 2 - 5 } & Analytical & BModes & Analytical & BModes \\
\hline 0 & 1.557 & 1.557 & 16.25 & 16.25 \\
\hline 1 & 1.902 & 1.902 & 16.76 & 16.76 \\
\hline 2 & 2.670 & 2.670 & 18.19 & 18.19 \\
\hline 3 & 3.582 & 3.582 & 20.35 & 20.35 \\
\hline 4 & 4.543 & 4.543 & 23.03 & 23.03 \\
\hline 5 & 5.522 & 5.522 & 26.04 & 26.04 \\
\hline 6 & 6.509 & 6.509 & 29.29 & 29.29 \\
\hline 7 & 7.501 & 7.501 & 32.70 & 32.70 \\
\hline 8 & 8.495 & 8.495 & 36.21 & 36.21 \\
\hline 9 & 9.490 & 9.490 & 39.80 & 39.80 \\
\hline 10 & 10.49 & 10.49 & 43.45 & 43.45 \\
\hline 11 & 11.48 & 11.48 & 47.14 & 47.15 \\
\hline 12 & 12.48 & 12.48 & 50.86 & 50.87 \\
\hline
\end{tabular}

\section{Conclusions and Future Plan}

All results indicate that BModes is capable of modeling and analyzing rotating blades and a wide range of tower support structures with a high degree of fidelity. Plans are underway to use it for a wide range of applications ranging from system identification to coupling with CFD software. BModes has been successfully used for finite element model updating of a turbine blade and a tower $^{10}$. An important future plan is to introduce a Timoshenko beam element, specialized to include rotational and hydrodynamic effects, and extend BModes to handle composite beams with non-isotropic material properties.

\section{Acknowledgment}

Thanks to Jason Jonkman from NREL for providing the ADAMS models of the towers used in this paper. This work was performed in support of the U.S. Department of Energy under contract number DE-AC36-83CH10093.

\section{References}

1. Jonkman, J.M.; Buhl Jr., M.L. FAST User's Guide. NREL/EL-500-29798. Golden, Colorado: National Renewable Energy Laboratory, 2005.

2. Bir, G. S., "Blades and Towers Modal Analysis Code (BModes): Verification of Blade Modal Analysis," Proceedings of the 47th AIAA Aerospace Sciences Conference and Wind Energy Symposium, Orlando, Florida, January 5-8, 2009.

3. Bir, G.S. User's Guide to BModes: Software for Computing Rotating Beam Coupled Modes. NREL TP-50038976. Golden, Colorado: National Renewable Energy Laboratory, 2005.

4. Yu, W.; Volovoi, V. V.; and Hodges, D. H.: "Validation of the Variational Asymptotic Beam Sectional Analysis," AIAA Journal, vol. 40, no. 10, 2002, pp. 2105-2113.

5. Bir, G.S. (2005). User's Guide to PreComp (Pre-Processor for Computing Composite Blade Properties). NREL/TP-500-38926. Golden, CO: National Renewable Energy Laboratory.

6. Malcolm, D.J., Laird D.L. "Identification and Use of Blade Physical Properties." Proceedings of the ASME/AIAA Wind Energy Symposium, Reno, Nevada, January 2005. 
7. Bir, G. S., and Chopra, I. "Status of the University of Maryland Advanced Rotorcraft Code (UMARC)." Presented at the American Helicopter Society Aeromechanics Specialist Conference. San Francisco, California, January 19-21, 1994.

8. Lee, C. H. and Newman, J. N. WAMIT® User Manual, Versions 6.3, 6.3PC, 6.3S, 6.3S-PC. Chestnut Hill, MA: WAMIT, Inc., 2006.

9. Wright, A. D., Smith C. E., Thresher R. W., and Wang, J. L. C., "Vibration Modes of Centrifugally Stiffened Beams," Journal of Applied Mechanics, Vol. 104, March 1982.

10. Bir, G.S.; Oyague, F. (2007). Estimation of Blade and Tower Properties for the Gearbox Research Collaborative Wind Turbine. 30 pp.; NREL Report No. TP-500-42250.

11. Jonkman, J. and Matha, D., "A Quantitative Comparison of the Responses of Three Floating Platform Concepts." European Offshore Wind 2009 Conference \& Exhibition, 14-16 September 2009, Stockholm; NREL/CP-500-46726. Golden, CO: National Renewable Energy Laboratory. 


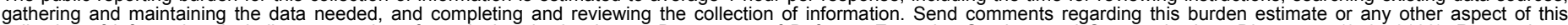

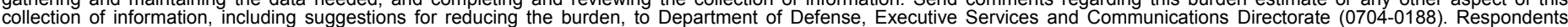

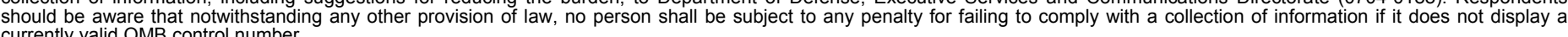

PLEASE DO NOT RETURN YOUR FORM TO THE ABOVE ORGANIZATION.
1. REPORT DATE (DD-MM-YYYY) April 2010
2. REPORT TYPE
Conference Paper
4. TITLE AND SUBTITLE
Verification of BModes: Rotary Beam and Tower Modal Analysis Code

3. DATES COVERED (From - To) April 12-15, 2010

5a. CONTRACT NUMBER

DE-AC36-08-GO28308

5b. GRANT NUMBER

5c. PROGRAM ELEMENT NUMBER

5d. PROJECT NUMBER

NREL/CP-500-47953

5e. TASK NUMBER

WE10.3112

5f. WORK UNIT NUMBER
7. PERFORMING ORGANIZATION NAME(S) AND ADDRESS(ES) National Renewable Energy Laboratory 1617 Cole Blvd. Golden, CO 80401-3393

9. SPONSORING/MONITORING AGENCY NAME(S) AND ADDRESS(ES)

\author{
8. PERFORMING ORGANIZATION \\ REPORT NUMBER \\ NREL/CP-500-47953
}

10. SPONSOR/MONITOR'S ACRONYM(S) NREL

11. SPONSORING/MONITORING AGENCY REPORT NUMBER

12. DISTRIBUTION AVAILABILITY STATEMENT

National Technical Information Service

U.S. Department of Commerce

5285 Port Royal Road

Springfield, VA 22161

\section{SUPPLEMENTARY NOTES}

\section{ABSTRACT (Maximum 200 Words)}

This paper describes verification of BModes, a finite-element code developed to provide coupled modes for the blades and tower of a wind turbine. The blades, which may be rotating or non-rotating, and the towers, whether onshore or offshore, are modeled using specialized 15-dof beam finite elements. Both blade and tower models allow a tip attachment, which is assumed to be rigid body with six moments of inertia, and a mass centroid that may be offset from the blade or tower axis. Examples of tip attachments are aerodynamic brakes for blades and nacelle-rotor subassembly for towers. BModes modeling allows for tower supports including tension wires, floating platforms, and monopiles on elastic foundations. Coupled modes (implying coupling of flap, lag, axial, and torsional motions) are required for modeling major flexible components in a modal-based, aeroelastic code such as FAST1. These are also required for validation of turbine models using experimental data, modal-based fatigue analysis, controls design, and understanding aeroelastic-stability behavior of turbines. Verification studies began with uniform tower models, with and without tip inertia, and progressed to realistic towers. For the floating turbine, we accounted for the effects of hydrodynamic inertia, hydrostatic restoring, and mooring lines stiffness. For the monopole-supported tower, we accounted for distributed hydrodynamic mass on the submerged part of the tower and for distributed foundation stiffness. Finally, we verified a model of a blade carrying tip mass and rotating at different speeds (verifications).

\section{SUBJECT TERMS}

Bmodes; wind turbine modal analysis code; floating platforms; modeling

\begin{tabular}{|c|c|c|c|c|}
\hline 16. SECURITY & CLASSIFICATI & N OF: & 17. LIMITATION & 18. NUMBER \\
\hline $\begin{array}{l}\text { a. REPORT } \\
\text { Unclassified }\end{array}$ & $\begin{array}{l}\text { b. ABSTRACT } \\
\text { Unclassified }\end{array}$ & $\begin{array}{l}\text { c. THIS PAGE } \\
\text { Unclassified }\end{array}$ & $\begin{array}{c}\text { OF ABSTRACT } \\
\text { UL }\end{array}$ & \\
\hline
\end{tabular}

19a. NAME OF RESPONSIBLE PERSON

19b. TELEPHONE NUMBER (Include area code) 